\title{
LOS AUTORRETRATOS DE BALTASAR DE ECHAVE ORIO
}

\author{
José Guadalupe Victoria
}

\author{
Éste, que ves, engaño colorido, \\ que del arte ostentando los primores, \\ con falsos silogismos de colores \\ es cauteloso engaño del sentido...
}

SOR JUANa Inés de Ia CRUz

\section{Las obras}

En un estudio reciente ${ }^{1}$ hemos atribuido varias pinturas al ilustre pintor de origen vasco. En estas líneas nos interesa tratar, de modo particular, dos de ellas. La primera es el gran cuadro conservado en la antigua iglesia franciscana de Texcoco (hoy catedral) cuyo tema alude a la Última Cena (lienzo sobre tabla; $4.70 \times 3.00 \mathrm{~m}$, fig, 1). El segundo cuadro representa El Pentecostés (lienzo sobre tabla, fig. 2); y se conserva en la iglesia de La Profesa, de la ciudad de México.

La importancia de estos cuadros estriba en que, en ambos, uno de los personajes dirige la mirada hacia el espectador (figs. 3 y 4). Detalle aparentemente banal, pero que, visto con cuidado, ha hecho pensar que se trata de sendos autorretratos. Uno de los primeros en percatarse de este detalle fue Abelardo Carrillo y Gariel, respecto al cuadro sito en la iglesia de La Profesa. ${ }^{2}$ En cuanto al posible autorretrato que aparece en el cuadro de la Última Cena, creo que hemos sido los primeros en remarcarlo. ${ }^{3}$

Ahora bien, el lector medianamente familiarizado con la bibliografía acerca de la pintura novohispana, sabe que Echave Orio escribió un libro sobre el origen de la lengua vascuence. En dicha obra, titulada

1 Guadalupe Victoria Vicencio, Les problèmes de la peinture en Nouvelle-Espagne entre la Renaissance et le Baroque. 1525-1625, Paris, Université de Paris X Nanterre, 1982. Thèse de troisième cycle en Histoire de l'Art et Archaeologie.

2 Abelardo Carrillo y Gariel, Técnica de la pintura de Nueva España, lámina 10.

3 Guadalupe Victoria Vicencio, op , cit, p 199 . Con posterioridad a la redacción de este artículo, ha aparecido el interesante artículo de Elisa Vargas Luigo acerca de "El retrato de donantes y el autorretrato en la pintura novohispana" (Anales del Ins. tituto de Investigaciones Estéticas, núm. 51, p.p. 13-20, México, 1983) donde se refiere a los autorretratos de Echave Orio, diciendo que "en ambas obras el parecido que ofrece el personaje con el grabado que se reconoce como setrato de dicho pintor, es efectivamente muy grande y en ambos casos también el carácter anímico que ostenta el viril rostro barbado, es el mismo. Por tanto, esta atribución es sin duda la más fundamentada". 
Discursos de la antigüedad de la lengua cántabra $\ldots,{ }^{4}$ el célebre artista incluyó, a manera de frontispicio, un grabado donde aparece su escudo nobiliario, acompañado por un espléndido autorretrato (figs. 5 y 6 ), cuya. descripción sucinta fue hecha por Manuel Toussaint, quien dice: "es un hombre [Echave Orió] de escaso cabello corto, barba rizada también escasa, y bigote. En la mano tiene la pluma y el pincel, y alrededor una leyenda latina..." ${ }_{5}$ La leyenda reza así: PATRIA ET PENICILLVM ET CALAM VM VTROQUE AE QVE ARTIFEX, D. D. Hay que agregar, a la descripción de Toussaint, que el pintor aparece vestido a la usanza de la época, con gola, capa y está retratado en posición de tres. cuartos de perfil. El grabado fue hecho en madera, en la ciudad de México, el año de 1607.

Una comparación atenta y detenida entre las pinturas mencionadas y el grabado, permite afirmar que efectivamente se trata de dos autorretratos del pintor.

En el cuadro de la ćltima Cena la figura está retratada en tres cuartos de perfil; se trata de un hombre de mediana edad, cabeza bien proporcionada, pelo muy cor to y frente despejada. Sus rasgos faciales están trazados de modo firme: ojos grandes, nariz aquilina y labios delgados; ostenta barba de regular espesor.

El carácter de retrato de esta figura se acentúa por el hecho de ser el único de los personajes que mira hacia el espectador; mientras que los otros prestan su atención al momento de la consagración del pan y el vino, o bien comentan el mismo acontecimiento.

El personaje de la pintura del Pentecostés delata mayor edad que el del cuadro antes mencionado. Aunque sus rasgos físicos son muy parecidos: cabeza bien proporcionada, dispuesta en tres cuartos de perfil para dirigir la mirada fuera de la escena principal, escaso cabello rizado y frente amplia, ojos grandes, nariz aquilina y barba de regular espesor.

Obsérvese otra vez el retrato de Echave, incluido en el frontis de su libro, y se caerá en la cuenta de que es el mismo personaje, sin olvidar la diferencia de técnica entre las obras; además de que, en el caso del dibujo, estamos ante una representación que, lo que pretende, es resaltar la personalidad del pintor-escritor. De ahí que Echave Orio aparezca elegantemente vestido y muestre con harto orgullo la pluma y el pincel, símbolos de las artes que cultivaba.

4 Baltasar de Echave Orio, Discursos de la antigüedad de la lengua cántabra...., México, Imprenta de Enrico Martínez, 1607. El subrayado es nuestro.

э Manuel Toussaint, Pintura colonial en México, p. 87. 
Sin embargo, a nuestro modo de ver, lo más importante de esta cuestión no es el hecho de saber solamente que se trata de dos retratos de Echave Orio, sino tratar de indagar por qué quiso retratarse el pintor. Esto nos lleva a hacer algunas consideraciones acerca del retrato, durante el primer siglo de vida novohispana.

Por las circunstancias en que surgió la creación pictórica en el virreinato, no puede hablarse del retrato como género pictórico independiente. ${ }^{\circ}$ Lo cual no impidió para que, tanto en pintura mural como en pintura al óleo, se produjera una cantidad considerable de retratos. Por ejemplo las series de retratos de los virreyes y de los arzobispos que ornaban las salas del Palacio y de la Catedral de México. Sin embargo, a ningún espectador escapa que el convencionalismo con que fueron realizadas estas obras impide considerarlas como auténticos y verdaderos retratos; al menos tal como se entendía dicha práctica en Europa

En pintura mural existe también un tipo de retrato donde, con buena dosis de convencionalismo, se advierte la intención de los artistas por representar -retratar, mejor dicho- a un personaje para perpetuar su memoria. Por ejemplo el retrato del padre Martín de Valencia que se conserva en el claustro dominico de Tepetlaoztoc

Por lo anterior nos parece significativo que Echave Orio haya sido uno de los escasos pintores que realizara un tipo de representación retratística donde el personaje forma parte de la composición; es parte del tema mismo, para decirlo con otras palabras. De esa manera el pintor salvaba dos obstáculos: uno, la casi segura prohibición que existió acerca de retratar personajes laicos dentro de una composición religiosa; y otro, el no alterar la propia composición de la pintura, tal como ocurría en las figuras con retratos de donante, que por cierto son muy escasas en esa época, aquí en la Nueva España.

Pero, retomemos la pregunta planteada líneas arriba. ¿Por qué habrá querido autorretratarse Baltasar de Echave Orio? Un intento de respuesta nos parece que puede hallarse al recordar un aspecto de la vida del pintor: su condición de escritor. Sí, porque fue uno de los pocos que, hasta donde se sabe, además de pintar, escribia; lo cual ha hecho pensar que su bagaje cultural era suficientemente amplio. Parece corroborar lo anterior el magnífico grabado incluido en su libro. Tan seguro estaba Echave Orio de su valía como pintor y escritor que no dudó en hacer rodear su retrato con la inscripción latina transcrita líneas

6 Guadalupe Victoria Vicencio, op. cit, segunda parte. 
arriba y cuya traducción aproximada sería: Patria, el arífice dedicó, equitativamente, tanto al pincel como a la pluma. * Así, tenemos que en éi se conjugaba un doble papel artístico tal como en España había sido, por ejemplo, Francisco Pacheco, aunque los escritos de éste fueran de naturaleza distinta.

Esta preocupación de Echave Orio por resaltar su doble papel de artista parece bastante lógica si recordamos que, en la misma época, en España se daba una lucha tenaz, por parte de los pintores, para logray que su arte (su oficio, si se prefiere) alcanzara la categoría de arte liberal. Dicho propósito llamó la atención de artistas como El Greco y Vicente Carducho, entre los más importantes.

El problema de la "nobleza de la pintura" no era particular de España, sino que antes se había dado en Italia. Y sin duda, como certeramente lo han visto Anthony Blunt ${ }^{7}$ y Julián Gállego, ${ }^{8}$ estaba en relación con la posición social de los artistas, que es tanto como hablar de la pugna entre las antiguas instituciones del gremio y la cofradía y las modernas agrupaciones en academias.

Por supuesto que en un medio artístico de avant-garde como era el de Italia, el problema se resolvió desde mediados de siglo xvı. Pero en España, siempre un tanto arrierée en cuanto a novedades artísticas se refiere, la lucha se prolongará hasta los tiempos de Velázquez. ${ }^{9}$

Para volver al caso particular que llama nuestra atención, diremos que es probable que tal tipo de preocupaciones se hayan dejado sentir en el medio novohispano; y que de alguna manera los artistas quisieran mostrar que tenían conciencia del problema. Sin embargo, debido a las limitaciones de expresión artistica imperantes, no fue posible que lo manifestaran de manera más abierta. Además, porque estando la pintura prácticamente al servicio de la Iglesia, era casi imposible que los artistas pensaran en autorretratarse. En todo caso era más factible hacerlo a través de grabados. No obstante, aunque el caso de Echave Orio es excepcional, existen ejemplos similares y contemporáneos: pensamos en el retrato del poeta Arias de Villalobos incluido en su Canto Intitulado Mercurio... (México, 1609).

* Agxadezco al profesor Bulmaro Reyes la traducción de este texto.

7 Anthony Blunt, La teoria de las artes en Italia $1450-1600$, Pról. y agenda bibliográfica por José Luis Checa Cremades, Madrid, Ediciones Cátedra, 1979, 175 p.

8 Julián Gállego, El pintor de artesano a artista, Granada, Universidad de Granada, Departamento de Historia del Arte, 1976, 283 p.

9 Ibid. 
Echave Orio sería, pues, uno de los pocos artistas que, al conjugar el papel de pintor-escritor, quiso dejar testimonio de su admiración y devoción por ambas artes. Los dos de gran nobleza. En la leyenda latina es clara su intención por afirmar que se ha dedicado equitativamente a una y a otra.

Por último señalaremos que si Echave Orio decidió autorretratarse en dos de sus lienzos es porque estaba seguro de su valía como artista. Los cuadros, creemos, fueron realizados en el momento de mayor éxito artistico. Luego entonces, ¿por el hecho de retratarse, será que no quiso firmar sus cuadros? Si así fue, debemos agradecerle que haya preferido otra firma no menos segura, aunque sí más enigmática, como son estos que creemos sus autorretratos. 
DOI: http://dx.doi.org/10.22201/iie.18703062e.1983.53.1211 


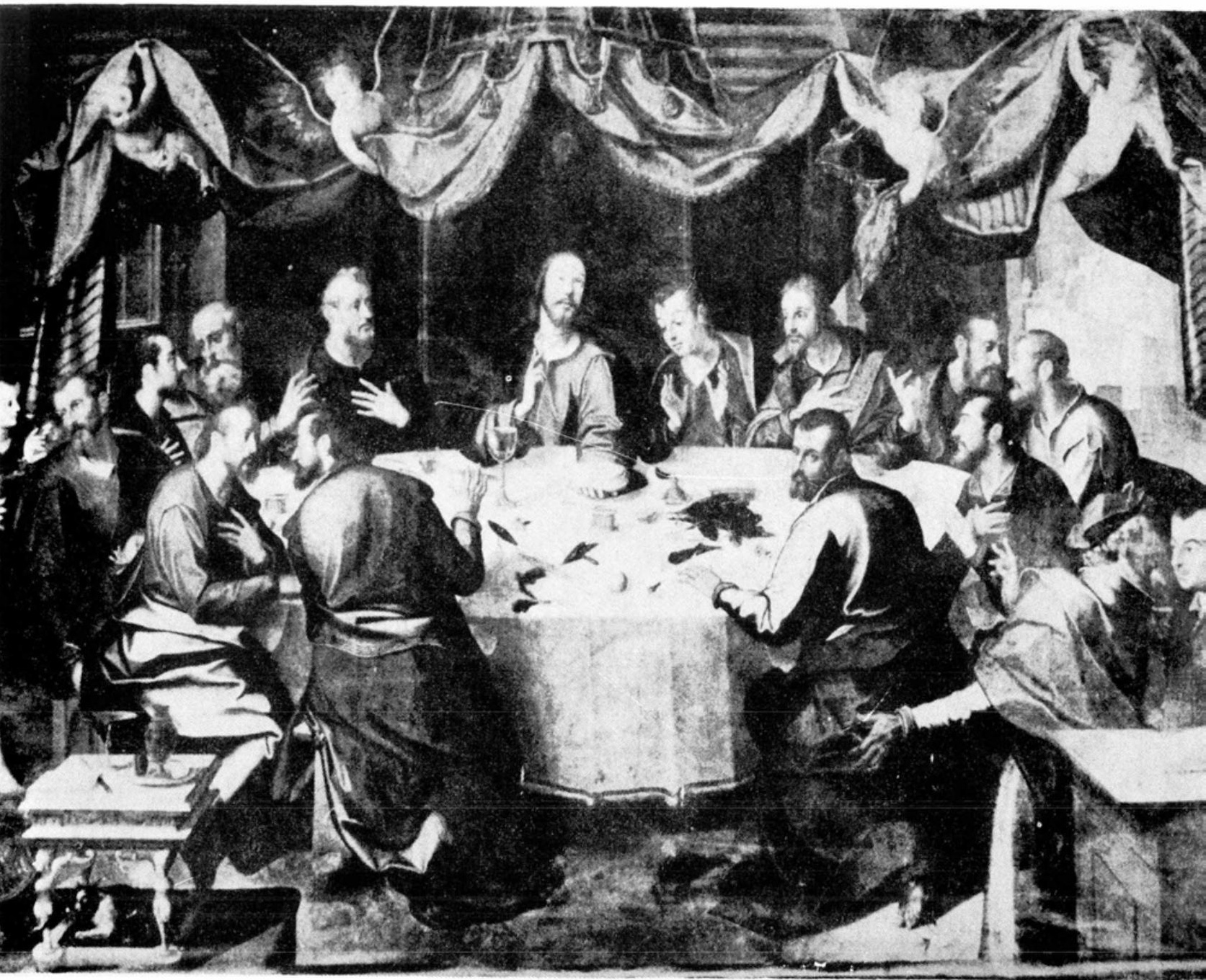

Figura 1. Baltasar de Echave Orio. La Última Cena.

Iglesia del Convento franciscano de San Antonio. Texcoco, Méx. Obsérvense detenidamente los rostros de cada uno de los personajes y compárense con los de las obras firmadas por Echave Orio; se caerá en la cuenta que la atribución a ese pintor es 


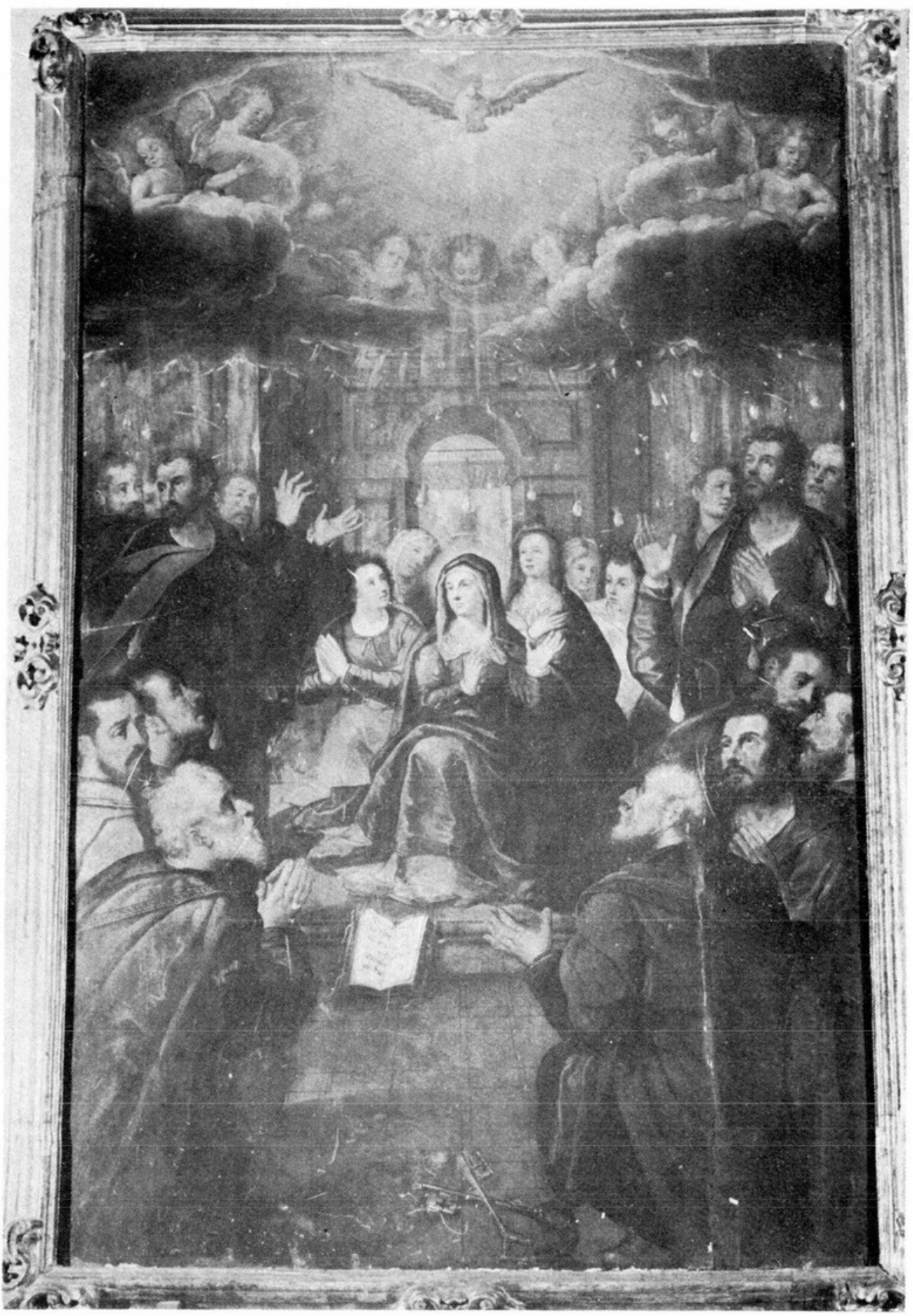

Figura 2. Baltasar de Echave Orio. El Pentecostés. Iglesia de la Profesa, México, D. F. La segunda figura del ángulo inferior izquierdo es la que tradicionalmente se ha considerado como autorretrato del pintor. 
DOI: http://dx.doi.org/10.22201/iie.18703062e.1983.53.1211
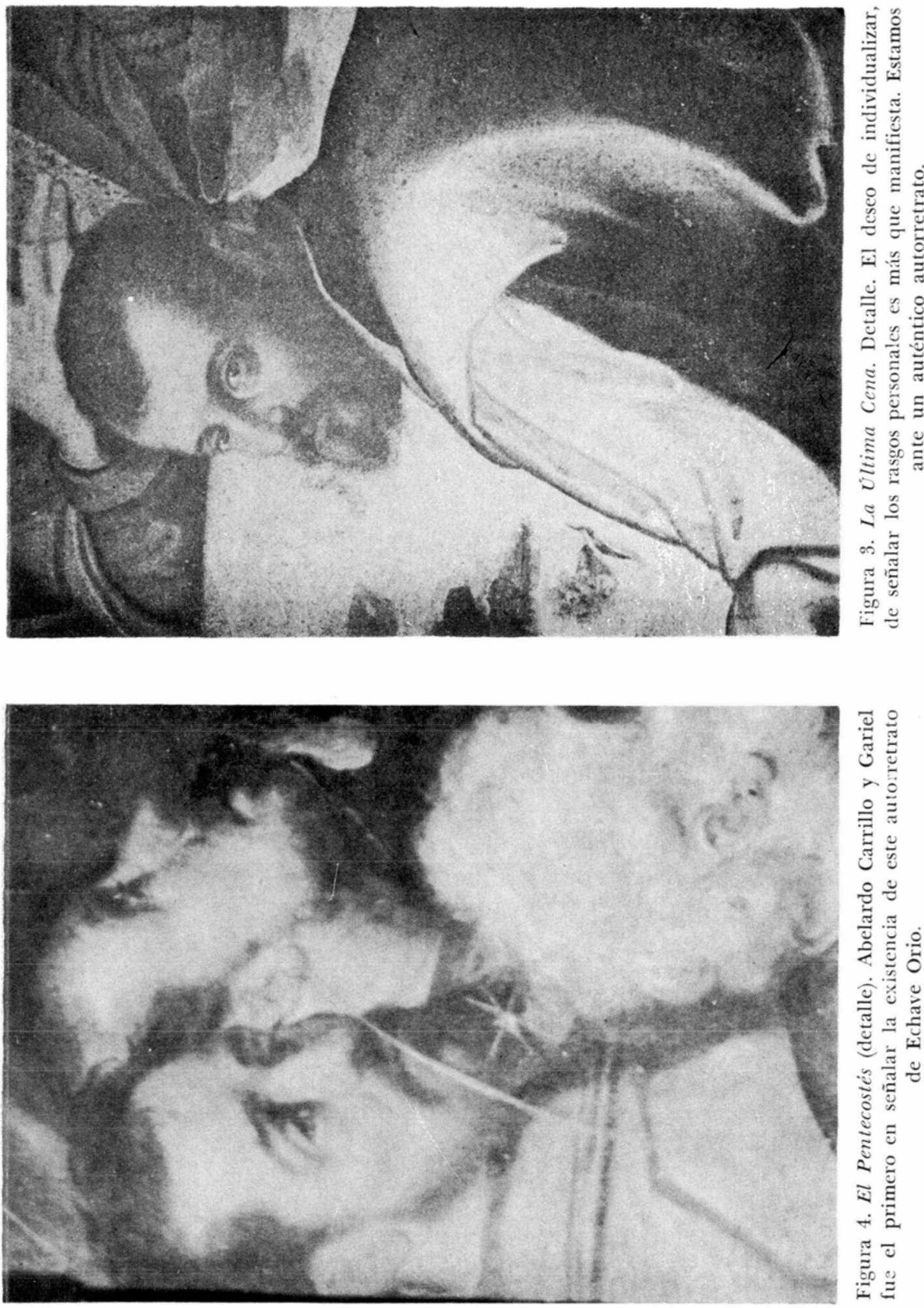

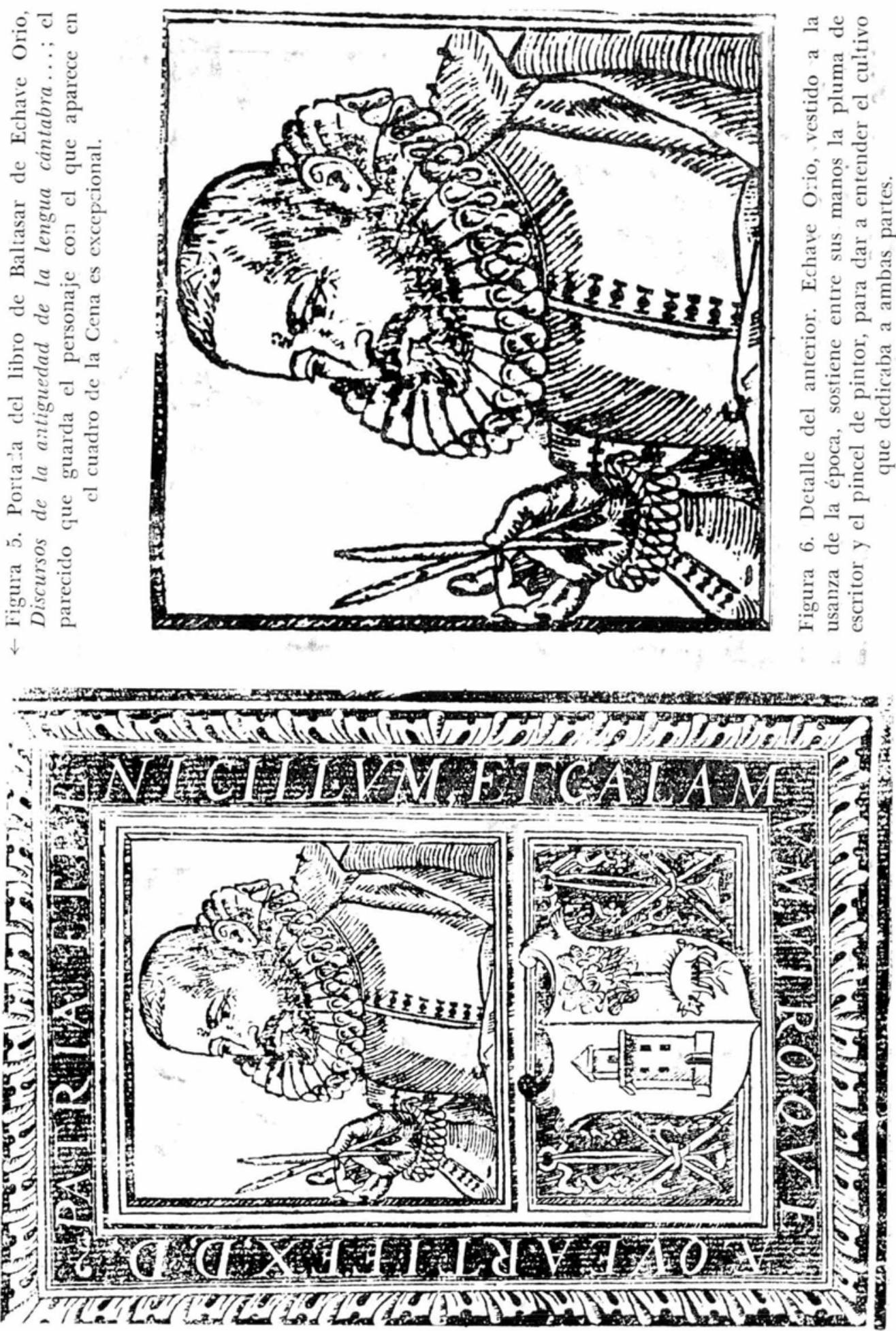